\title{
IMPORTÂNCIA DO SECTOR INFORMAL DA ECONOMIA URBANA EM PAÍSES DA ÁFRICA SUBSARIANA
}

ILÍDIO DO AMARAL ${ }^{1}$

\author{
'There is mounting evidence that the informal sector \\ of African economies is far larger and more complex \\ than previously thought' (MIRACLE et al., 1980). \\ 'O informal é, não obstante, o principal regulador \\ económico e social e revela um dinamismo \\ projectado para o futuro' (Hugon, 1999).
}

\begin{abstract}
Resumo-Em homenagem a CARlos Alberto Medeiros, o autor do artigo, depois de recordar, no Preâmbulo, alguns pontos importantes da brilhante carreira universitária de quem foi seu aluno e colaborador e das relações mútuas de amizade e respeito, aborda o tema da importância do sector informal da economia urbana em países da África Subsariana em duas partes - 1. Sobre o informal e a informalidade da economia urbana; e 2. Sobre a multi-segmentação do sector informal - com uma Conclusão. Produtos de reflexão ao longo de alguns anos, com base em observações pessoais no terreno, em inúmeras consultas bibliográficas e permutas de conhecimentos com outros especialistas das ciências sociais, o autor oferece ao homenageado as primícias de um livro em elaboração.

A primeira parte começa com reflexões sobre a expressão 'sector informal', desde há muito universalizada, e de outras que ainda são usadas, a validade do dualismo formal-informal como instrumento de análise, prosseguindo com exemplos de diferenças entre os dois sectores (Quadro I), às relações entre eles e à existência de formas intermédias, e dados sobre a importância e expansão do informal, que assegura a sobrevivência da maioria dos habitantes das cidades. A segunda contém matérias sobre a miríade de actividades, pequenos negócios ou ofícios, individuais, familiares ou mesmo 'empresariais' que animam mercados e ruas, com forte expressão dos produtores e vendedores ambulantes (papel primordial das mulheres), muitos deles saídos do mundo rural e imigrantes estrangeiros fixados há pouco tempo nas urbes (Quadro II). Numa proposta de outro autor (Quadro III) ressaltam as dificuldades da construção de uma tipologia das numerosas micro-actividades e de traçar fronteiras nítidas entre o formal e o informal.
\end{abstract}

${ }^{1}$ Geógrafo. Professor Catedrático Jubilado da Faculdade de Letras da Universidade de Lisboa. Director do Centro de Geografia do Instituto de Investigação Científica Tropical. 
Em Conclusão são sublinhadas a realidade, a complexidade, a expansão e a importância incontestáveis do sector informal da economia urbana. Daí a necessidade de o estudar no terreno, tendo em conta o seu enquadramento mais amplo, e não como uma forma marginal ou marginalizada, mas como um fenómeno estrutural.

Palavras-chave: África subsariana, países em desenvolvimento, economia urbana, sector informal e sector formal, informalidade; actividades multi-segmentadas, pequenos ofícios, emprego e rendimentos, pobreza e sobrevivência.

Abstract - THE ROLE OF THE INFORMAL SECTOR IN THE URBAN ECONOMY OF THE SUB-SAHARIAN AFRICAN COUNTRIES'. In this paper, presented as a tribute to CARLOS Alberto Medeiros, the author begins by evoking some of the most important moments in the brilliant academic career of his former student and collaborator, as well as the feelings of mutual friendship and respect that bind the two. The subject of the importance of the informal sector in the urban economy of Sub-Saharan African countries is then addressed in two parts -1 . On the informal nature and informality of the urban economy; and 2. On the multi-segmentation of the informal sector-, which are followed by a Conclusion. The result of many years of careful reflection and analysis, based on field observation, countless literature surveys and exchanges of knowledge with other specialists from the social sciences, this paper is actually an early version of part of a book currently under preparation, and is offered as such as a gift accompanying this tribute.

The first part of the paper begins with a reflection on the expression 'informal sector' (for long in current usage) and others still being used, as well on the validity of the formal/informal dicotomy as an analytical instrument, and proceeds by presenting examples of the differences between these two sectors (Table I), their inter-relationships, the existence of hybrid forms and some data on the importance and expansion of the informal sector, which is responsible for ensuring the livelihood of most city inhabitants. The second part focuses on the myriad activities and small-scale individual, family and even 'firm-like' businesses and trades that bring the streets and markets to life. Street hawkers and producers, among whom the women play a central role, predominate, many of whom are newcomers to the city that have just arrived from the countryside, or from abroad in the case of the immigrants (Table II). According to another author (Table III), it is particularly difficult to create a taxonomy of these multiple micro-activities, and to draw a clear-cut distinction between formal and informal activities.

In the concluding remarks, attention is drawn to the unquestionable reality, complexity, expansion and importance of the informal sector of the urban economy. Hence the need to study it in the field while bearing in mind its wider context and to regard it as a structural feature rather than a marginal or marginalized phenomenon.

Key words: Sub-Saharan Africa, developing countries, urban economy, formal and informal sector; informality, multi-segmented activities, small trades and businesses; employment and income, poverty, livelihoods.

Résumé - Le role du Secteur informel de L'economie Urbaine en Afrique au Sud DU SAHARA. Pour rendre hommage à Carlos Alberto Medeiros, l'auteur, après avoir remémoré, en préambule, quelques aspects importants de la brillante carrière universitaire de qui fut son élève et collaborateur, ainsi que leurs relations mutuelles d'amitié et de respect, aborde, en deux points, l'importance du secteur informel de l'économie urbaine dans les pays d'Afrique au Sud du Sahara: 1. L'informel et l'informalité de l'économie urbaine ; 2. La multi-segmentation du secteur informel. 
Résultant d'une réflexion de plusieurs années, basée sur des obs ervations personnelles de terrain, d'innombrables lectures et des échanges avec d'autres spécialistes de sciences sociales, ce sont les prémices d'un livre en cours d'élaboration que l'auteur offre à son collègue et ami.

La première partie commence par des réflexions sur l'expression 'secteur informel', généralisée il y a longtemps, et sur d'autres, encore en usage ; sur la validité du dualisme formel-informel comme instrument d'analyse. Sont donnés quelques exemples des différences entre les deux secteurs (Tableau I), de leurs relations et des formes intermédiaires. Sont fournies des données sur l'importance et l'expansion de l'informel, qui assure la survie de la majorité des citadins. La deuxième partie traite de la myriade de petites activités (petits métiers individuels, familiaux ou constitués en micro-entreprises), qui animent marchés et rues, avec une forte représentation des producteurs et vendeurs ambulants, entre lesquels de nombreuses femmes. Beuacoup viennent du monde rural ou de pays voisins (Tableau II). Il est difficile d'élaborer une typologie des innombrables micro-activités du secteur informel et de tracer une frontière précise entre formel e informel, comme le montre le Tableau III, due à un autre auteur. En conclusion, on souligne la réalité, la complexité, l'expansion et l'importance incontestables du secteur informel dans l'économie urbaine. D'où la nécessité de l'étudier sur le terrain, de le situer dans son contexte et de le considérer, non comme une forme marginale, mais comme un phénomène structurel.

Mots-clés: Afrique subsaharienne, pays en développement, économie urbaine, secteur informel et secteur formel, informalité, activités multi-segmentées, petits métiers, emploi et revenus, pauvreté et survie.

\section{PREÂMBULO}

É com muito gosto que presto homenagem ao querido Amigo e Colega Carlos Alberto Macedo de Medeiros. Desde há muito anos que estamos ligados por uma sólida amizade e por elevada consideração, e pelo cultivo da mesma disciplina do conhecimento: a Geografia. O nosso primeiro encontro teve lugar em 1960, quando o recebi como aluno de Geografia Física I, cadeira inicial da licenciatura que regi, durante muitos anos, pelo prazer de receber os caloiros. Voltou a ser meu aluno, manifestando-se sempre como um dos melhores e mais bem classificados.

Interessado na Geografia regional, com evidente curiosidade pela das regiões tropicais, área da minha particular predilecção e dedicação, foi com prazer que o vi aceitar, depois da sua licenciatura em Lisboa, um estágio no Instituto de Geografia da Universidade de Bordéus e no Centro de Estudos de Geografia Tropical (CEGET) do Centre National de la Recherche Scientifique, sob a orientação de um Mestre e Amigo, o Professor Guy Lasserre, e apoiado por outros geógrafos que ganhavam prestígio internacional pelos seus trabalhos sobre temas de territórios dessa faixa do Globo. Acompanhei o seu percurso, visitei-o em Bordéus, regozijei-me com a sua tese de doutoramento de $3 .^{\circ} \mathrm{Ciclo}$, L'Evolution récente de la sucrerie Beauport (Guadeloupe), 1970. Era o primeiro (e único) geógrafo português com diploma académico em Geografia tropical. 
Por isso mesmo lhe foi feito o convite para leccionar na emergente secção de Geografia dos Cursos de Letras da Universidade de Luanda, em estabelecimento fixado na cidade de Sá da Bandeira (devolvido o nome de Lubango depois da Independência de Angola) e para aí escolher um tema destinado a tese de doutoramento. Do mesmo modo foi convidada a sua mulher, Isabel Marques Medeiros, que também fora minha distinta aluna no primeiro ano das minhas actividades de docente universitário. Fazendo parte de um pequeno grupo sob a minha direcção, não há palavras para lhes agradecer os imensos testemunhos de amizade e o quanto fizeram para o desenvolvimento, com nível superior, não só daquela secção e do embrião de núcleo para a investigação científica (o GEGU, Gabinete de Estudos de Geografia do Ultramar), mas também para remodelar e consolidar a Delegação da Universidade de Luanda, numa altura em que aceitei essa responsabilidade.

Mesmo ausente, pois nunca deixei de residir e trabalhar em Lisboa, mas com deslocações frequentes ao Lubango, pude contar com a competência e dedicação do Carlos Alberto e da Isabel Medeiros, do saudoso Joaquim Manuel Bragança Lino da Silva, nosso grande amigo e companheiro de trabalhos de campo, de colegas de outras secções, de alunos e de funcionários ali residentes. Com elementos dos três grupos, sob minha proposta, foi criada uma Comissão encarregada da gestão corrente, devidamente autorizada pelo Magnífico Reitor, Prof. Doutor Ivo Soares, que me deu a maior liberdade para resolver os problemas da Delegação. Posso afirmar que foi a primeira experiência de 'gestão democrática' de uma escola.

A permanência de Carlos Alberto Medeiros em Sá da Bandeira permitiu-lhe elaborar a excelente monografia A Colonização das Terras Altas da Huíla (Angola), 1976, tese de doutoramento feita na Universidade de Lisboa, com a classificação mais alta, e que teve o prémio Abílio Lopes do Rego, da Academia das Ciências de Lisboa, além de outros estudos que marcaram a sua carreira de 'tropicalista'. Regressado a Lisboa, findo o tempo que fora aprazado, passou a interessar-se mais por temas de Portugal e de outras áreas do Globo. Prosseguiu uma carreira académica brilhante, preenchida com muitas actividades docentes e de investigação, muitas publicações, e da nossa Universidade foi Vice-Reitor durante alguns anos.

É com a recordação de muitas conversas que tive com ele e com a Isabel Medeiros (mais interessada nas coisas urbanas e económicas) sobre aspectos geográficos das regiões tropicais, sobretudo os angolanos, que lhe dedico o texto sobre a importância do sector informal da economia urbana em países em desenvolvimento. A escolha do tema tem significado duplo. Um deles está no que já ficou escrito. O outro é o de se tratar de um conjunto de apontamentos e reflexões de um livro que tenho em elaboração desde há vários anos, depois de ter publicado, em 1968, Luanda. Estudo de geografia urbana, cidade berço da minha família e onde eu nasci.

Muitos compromissos afastaram-me desse labor, com relevo para a preocupação de cumprir as fases de um bibliografia programada: estudos de geo- 
grafia urbana, de geomorfologia, de fronteiras e estado, de geografia histórica, a maior parte baseada nos conhecimentos sobre Angola e outras partes do continente africano. Há cerca de meia dúzia de anos retomei os meus apontamentos e reflexões sobre o sector informal da economia urbana em países em desenvolvimento, sobretudo os africanos ao sul do Sara, e também sobre os processos da globalização, para além da mundialização pela generalização da economia liberal (Morin, 2000), os dois temas que constituem a fase actual das minhas preocupações geográficas.

Do primeiro apraz-me oferecer ao Carlos Alberto Medeiros as primícias do livro que está em cuidada elaboração, sem saber ainda quando lhe colocarei o último ponto final. Sublinho, entretanto, que os estudos e reflexões abrangem apenas as cidades; não me tenho debruçado sobre o mundo rural, a não ser em casos específicos, como quando é preciso recorrer às migrações dos campos para as cidades, muito importantes no aumento demográfico destas e da sua heterogeneidade e complexidade económica, social e étnica.

\section{SOBRE O INFORMAL E A INFORMALIDADE DA ECONOMIA URBANA}

Em Luanda. Estudo de geografia urbana, referi-me à existência de um sector comercial informal, sem contudo ter usado esta palavra, dado que na altura nem ela nem o conceito estavam fixados na bibliografia geográfica ou de outros domínios das ciências sociais. Apareciam termos adjectivantes como 'espontâneo', 'tradicional', 'não estruturado', 'transitório', 'paralelo', 'inferior', 'marginal', e também a utilização de 'subterrâneo' e 'clandestino', ainda que se reconhecesse quanto eles não exprimiam, exactamente, o que se colhia da realidade. Mesmo hoje há quem conteste a expressão 'sector informal', sobretudo porque ela abarca um leque muito vasto de actividades, que não apenas as do comércio, tomado este no seu sentido restrito, porque são numerosas as ligações com o sector formal, e nem sempre é fácil marcar, com nitidez, as fronteiras entre eles.

Tida como inadequada, todavia ainda ninguém conseguiu forjar outra expressão que a substitua. Há até quem discuta sobre se o conceito de sector informal é ou não útil e, de igual modo, se o dualismo formal e informal constitui um instrumento válido de análise (BREMAN, 1976; AMIN, 1996; McGeE, 1996; WARING, 1999). Sublinho os factos da volumosa bibliografia sobre o fenómeno, em variadas línguas (citarei apenas alguns textos de maior interesse, seleccionados, sobretudo, entre os mais recentes), ter consolidado a utilização da expressão 'sector informal' e do estudo dele ter posto em causa teorias económicas aceites como universais. Sacrifico o seu historial para me colocar na posição da maioria dos estudiosos que evoca, sobretudo, relatórios da Organização Internacional do Trabalho (OIT) nos quais, desde 1972, se fixaram o uso e o conceito de sector informal e, derivando daí, o de informalidade. 
Em notas e recensões que publiquei nas revistas Finisterra e Garcia de Orta-Série de Geografia, ambas de Lisboa, dei conta de alguns estudos significativos (AMARAL, 1985, 1987 e 1988), não esquecendo as notáveis contribuições de Milton Santos, Amigo e Colega brasileiro que recordo com saudades, nomeadamente o seu livro $O$ espaço partilhado: os dois circuitos da economia urbana dos países em desenvolvimento, com edições em francês (SANTOS, 1975), em inglês e em brasileiro, obra muito utilizada por quantos estudam geografia urbana e disciplinas afins. Para não alongar o texto reuni no quadro I, de forma muito sintética, algumas diferenças entre os sectores formal e informal. Por aqui e pelos quadros seguintes se pode ver como não é fácil estabelecer uma definição exacta, em poucas palavras, de sector informal.

Está provado que nas cidades dos países em desenvolvimento, com manifestas dificuldades do Estado e do sector dito formal darem respostas às necessidades básicas da população, o sector informal supre essas faltas, quer nas áreas da produção (agricultura peri-urbana, artesanato e formas industriais simples), da distribuição (comércio e serviços), da construção (habitação), dos serviços sociais (educação e saúde) e, sobretudo, do emprego gerador de oportunidades salariais de uma grande parte da população, muitas vezes a maioria dos habitantes de uma aglomeração urbana. Estima-se que esse sector emprega uma percentagem elevada da população activa, permitindo a sua sobrevivência. Ele constitui, deste modo, um fenómeno estruturante e é inegável a sua importância estratégica.

Nenhuma simples dicotomia conseguiria resumir satisfatoriamente a situação, mesmo numa única cidade. A análise em termos de dois sectores separados poderá ignorar as relações entre eles, escamoteando a existência de elementos intermediários (BRomley, 1979; Bromley e GERRY, 1979; e outros). Perante a perenidade e a vitalidade do sector informal, as capacidades inventivas e produtivas dos seus agentes, a constatação desse sector não ser um entrave para a expansão da economia urbana, e, muito pelo contrário, contribuir para ela, ganham relevo a necessidade de elaboração de métodos da análise rigorosa da realidade e de procura de soluções de integração.

Sabe-se bem quanto é mais fácil afirmar isso do que encontrar metodologia geral aplicável, indistintamente, a todas as cidades dos países em desenvolvimento nos vários continentes, com percursos históricos, culturais, económicos, sociais e políticos diferentes. O que se tem feito, em regra geral, é a utilização combinada de uma variedade de métodos empíricos e teóricos. E é do conhecimento comum a existência de três economias separadas mas interligadas: a formal, a informal e a global. Em 1998, num relatório do Programa das Nações Unidas para o Desenvolvimento (PNUD) acerca de África, se escrevia que os esforços para promover a intermediação financeira deveriam englobar os dois sectores, o formal e o informal, e as suas interligações, de modo a reforçar a solidez estrutural de um e as virtualidades dinâmicas do outro. Voltarei a este assunto mais adiante. 
Quadro I - Apresentação sintética de algumas diferenças entre os sectores formal e informal

Table I-Synthetic presentation of some differences between the formal and informal sectors

\begin{tabular}{|c|c|c|}
\hline & Formal & Informal \\
\hline Início & $\begin{array}{l}\text { Dependente de autorizações } \\
\text { oficiais }\end{array}$ & Conta apenas a iniciativa pessoal \\
\hline Organização & $\begin{array}{l}\text { Sociedades legalmente } \\
\text { constituídas }\end{array}$ & $\begin{array}{l}\text { Individual ou familiar, livre e } \\
\text { flexível }\end{array}$ \\
\hline Instalações & Obrigatórias & Geralmente inexistentes \\
\hline Capital de investimento & Elevado & Fraco \\
\hline Capital de reserva & Essencial & Geralmente inexistente \\
\hline Tecnologia & $\begin{array}{l}\text { Importada e de alto nível ou } \\
\text { reproduzida localmente }\end{array}$ & $\begin{array}{l}\text { Inexistente, ou primitiva e } \\
\text { adaptada }\end{array}$ \\
\hline Trabalho & $\begin{array}{l}\text { Reduzido em relação ao volume e } \\
\text { ao valor da produção }\end{array}$ & Abundante, sem especialização \\
\hline Salário e vinculo & $\begin{array}{l}\text { Ao abrigo de contrato de trabalho } \\
\text { segundo normas legais }\end{array}$ & $\begin{array}{l}\text { Acordado entre pessoas, sem } \\
\text { vínculo }\end{array}$ \\
\hline Armazenamento & $\begin{array}{l}\text { Grandes quantidades e/ou boa } \\
\text { qualidade }\end{array}$ & $\begin{array}{l}\text { Quando muito, pequenas } \\
\text { quantidades e de fraca qualidade }\end{array}$ \\
\hline Preços & Tabelados oficialmente & Objectos de regateio \\
\hline Crédito & $\begin{array}{l}\text { Operações bancárias; empréstimos } \\
\text { ou subsídios estatais; investimentos } \\
\text { estrangeiros }\end{array}$ & $\begin{array}{l}\text { Pessoal ou familiar; recurso a } \\
\text { 'instituições' tradicionais } \\
\text { (associações de poupança e } \\
\text { crédito, e 'banqueiros do povo') }\end{array}$ \\
\hline Margem de lucros & $\begin{array}{l}\text { Pequena por unidade mas alta pelo } \\
\text { volume de negócios; capitalização }\end{array}$ & $\begin{array}{l}\text { Elevada por unidade mas pequena } \\
\text { por volume de negócios; } \\
\text { capitalização rara }\end{array}$ \\
\hline Custos fixos & Substanciais & Não contabilizados \\
\hline $\begin{array}{l}\text { Contabilidade e } \\
\text { apresentação de contas }\end{array}$ & Ambas obrigatórias por lei & $\begin{array}{l}\text { Inexistentes ou, quando muito, a } \\
\text { primeira em moldes rudimentares }\end{array}$ \\
\hline $\begin{array}{l}\text { Reciclagem de } \\
\text { desperdícios }\end{array}$ & Raramente & Muito frequente \\
\hline Publicidade & $\begin{array}{l}\text { Importante e intensiva, por meios } \\
\text { próprios ou por via dos media }\end{array}$ & De pessoa a pessoa, quando existe \\
\hline Dependência do exterior & Grande, com contratos & Pequena ou nenhuma \\
\hline
\end{tabular}

(Fontes: PaIX, 1972; SAntos, 1975; Roberts, 1978; Amaral, 1988; ANdRADE, 1992)

Desde há muito se concluiu que as análises sócio-económicas do emprego subestimam o sector informal, uma vez que aqueles que aí trabalham não correspondem ao critério usual de pessoa empregada, sendo considerados, na 
maior parte dos casos, como desempregados, sem profissão ou inactivos. Testemunha isso a forma como são tidas (ou não são consideradas) as actividades do sector informal, bastando recordar os casos em que as estatísticas seguem, fielmente, as regras do sistema das Nações Unidas, que é altamente selectivo e não regista o modo como muitas pessoas do Globo asseguram a sua sobrevivência (WARING, 1999). Contudo, na maior parte dos países da África ao Sul do Sara, como em muitos de outros blocos continentais, também em desenvolvimento, pode-se dizer, sem sombra de dúvida, que o sector formal é apenas uma face da economia urbana, pois o informal tornou-se numericamente dominante, assumindo um peso significativo nos indicadores económicos (SETHURAMAN, 1976, 1977; OIT, 1981).Uma vasta literatura dos domínios das ciências sociais tem explorado a forma como os pobres, aqueles que não têm emprego estável na economia urbana, conseguem sobreviver e como a cidade, apesar da falta de empregos, chega a alimentar a sua população. O sector informal passou a ser considerado como o conjunto dos métodos de sobrevivência, com o desenvolvimento de um complexo de actividades não formais.

Contrariando muitas opiniões, nos anos de 80 e 90 do século passado houve um aumento exponencial do sector informal, em resultado de factores tão diversos como a crise económica, a contracção do mercado de emprego no sector formal e despedimento de trabalhadores, o aumento de rendimentos disponíveis no sector informal e das necessidades dos consumidores de bens e serviços (Gilbert e Gugler, 1982; Drakakis-Smith, 1990; Tinker, 1997). São realidades a expansão numérica das pequenas actividades ou pequenos ofícios, a simultaneidade da sua criação e do seu desaparecimento, a juventude dos agentes, a fraqueza de capital de investimento, a independência financeira vis-a-vis as instituições de crédito oficiais. E é visível como, muitas vezes, as pequenas actividades ou ofícios adquirem os carizes de modernidade.

Segundo um relatório de 1995 do Women's World Banking Forum estimava-se que, da população activa do Globo, mais de 500 milhões de pessoas desenvolviam as suas actividades no sector informal; as micro-empresas empregariam 50 a $60 \%$ da força de trabalho dos países em desenvolvimento e produziriam 20 a $40 \%$ do respectivo PIB. Análises da força de trabalho em algumas cidades africanas têm dado valores para além de $60 \%$ no sector informal. Em Marrocos, em 1982, serviços oficiais calculavam que cerca de $76 \%$ da população activa urbana tinha ocupações no sector informal, valor subestimado, segundo alguns observadores (ABDAIMI, 1989). No período de 1990-1995, na maioria dos países em desenvolvimento perto de $85 \%$ dos empregos criados foram no sector informal; na Índia estimava-se que, em muitas grandes cidades, apenas pouco mais de $10 \%$ da força de trabalho pertencia ao sector formal, público e privado.

São exemplares os resultados de uma análise do emprego no sector informal em Luanda, feita por Mário Adauta de Sousa em 1998, para mostrar a importância das suas actividades. De forma resumida reproduzirei as principais conclusões deste trabalho. De acordo com um inquérito oficial de 1995 sobre as 
condições de vida da população urbana, em cerca de 690 mil pessoas com emprego apenas $37 \%$ tinha actividades do sector formal; e da população feminina ( $48,6 \%$ daquele total), mais de $60 \%$ estava no informal, o que marca uma dominância da mão-de-obra feminina. Muitas outras conclusões puderam ser tiradas relativamente ao sector informal, em comparação com o formal, tais como o predomínio do analfabetismo e o menor número de anos de escolaridade; a superioridade da idade média dos indivíduos; as taxas de desemprego mais baixas, sendo o primeiro provedor de empregos (seguia-se-lhe a Administração Pública), ainda que os salários fossem baixos; a existência de muitos independentes, com relevo para os vendedores de rua, entre os quais predominavam os jovens; a verificação de que sustentava $54 \%$ das famílias, sendo importante a presença de famílias alargadas (cerca de 53\%); a proporção elevada de famílias dirigidas por mulheres sozinhas com filhos (duas vezes superior à do formal); o facto de conseguir gerar poupanças positivas (número dos agregados com poupanças negativas muito inferior ao do sector formal), mas também o de ter o maior índice de pobreza (entre 56 e $68 \%$ das famílias dadas como pobres); os ramos de actividades de produção de alimentos e bebidas, de transportes e de outras indústrias, da construção e do comércio eram os de maiores rendimentos (SousA, 1998).

Diversos estudos têm mostrado a importância da mobilidade entre os dois sectores da economia urbana, umas vezes nos dois sentidos, noutras até com maior peso do primeiro para o segundo. As suas relações com o desenvolvimento económico também não são tão lineares como as regras dos manuais. As dependências existem, se tivermos em conta que os pequenos produtores e vendedores, aparentemente independentes, dependem dos produtores e comerciantes do sector formal que lhes fornecem os materiais ou lhes proporcionam créditos. Muitas actividades de pequena escala surgiram em resposta às necessidades do sector formal e até podem continuar na sua dependência. Afinal os artigos vendidos nos mercados informais foram importados por grandes empresas, ou produzidos em fábricas locais, os trabalhos feitos em pequenas oficinas carecem de matérias primas fornecidas pelo sector formal. Outros exemplos das interligações entre os dois sectores está nos empregados domésticos de funcionários públicos ou de empregados de grandes empresas. Mais uma vez a oportunidade de emprego de pequena escala resulta da actividade de larga escala. Muitos empresários por conta própria aprenderam a profissão enquanto estiveram empregados numa grande empresa, desligando-se dela quando conseguiram juntar capital de arranque e assegurar os fornecimentos de matérias primas. E os dois sectores podem estar em competição: entre fábricas e artesanato, entre actividades comerciais, entre serviços de vários tipos (BIENEFELD, 1987). Também não são tão nítidas as fronteiras em domínios de fixação de preços.

Em anos recentes o crescimento do sector informal tem resultado de crises económicas que afectam, sobretudo, o sector formal. É elucidativo o que se passou em países do Sueste Asiático que tiveram forte expansão económica 
nos anos 80 e primeira metade dos 90 do século passado. A crise financeira e económica da segunda metade dos anos 90, com aprofundamento brutal em 1997, levou muita gente à ruína total. Assim sucedeu, por exemplo, com um rico e afamado corretor e agente imobiliário de Banguecoque, de 48 anos que, de um dia para outro, se viu sem nada e, para sobreviver, ingressou no sector informal, pedalando uma bicicleta como vendedor ambulante de sanduíches pelas ruas da cidade (YASMEEN, 2001). Muitos outros seguiram percursos idênticos, modificando a estrutura do mercado de pronto-a-comer barato, por um lado porque sucedeu numa altura em que se alteravam os hábitos dos citadinos, que trocavam, em números cada vez maiores, as suas comidas e bebidas tradicionais pelas de influência norte-americana (sanduíches, hamburgers, cachorros-quentes, batatas fritas, sumos de frutas, etc.). E sucedeu ainda que, em muitos casos, entraram em competição com as mulheres que detinham, tradicionalmente, esses nichos mercantis.

A existência de um sector intermédio complica não apenas um modelo dualista da economia urbana, mas também qualquer análise: as relações entre os dois sectores não são simples, nem lineares, pelo contrário, variadas e complexas (O'CONNOR, 1983 e 1986; AMARAL e CARNeIRo, 1987). Os estudiosos dividem-se entre a importância da unidade de organização económica e a forma de emprego, discutindo qual das duas deve ser tomada como base de distinção dos dois sectores; entre os que acreditam na importância da dinamização do sector informal, mas conservando as suas características positivas, nomeadamente a forte capacidade de criação de empregos, e os que discordam, criticando que seria preciso esquecer dois factores importantes, o papel essencial que desempenha o desemprego estrutural no desenvolvimento e reprodução do sector informal e a articulação deste com o formal, tido como dominante da economia. Naturalmente que a virtude estará na conciliação de pontos de vista, evitando-se o perigo de estudos isolados do informal como sector marginal (LOMNITZ, 1977).

\section{SOBRE A MULTISEGMENTAÇÃO DO SECTOR INFORMAL}

Inicio esta parte com transcrições, ligeiramente comentadas, de dois autores que se têm debruçado sobre cidades africanas: do francês PHILliPE Hugon e do angolano Pepetela, pseudónimo de Artur Carlos Pestana dos Santos. Cada um deles, à sua maneira, sintetizaram de forma cinemática imagens de mercados do sector informal.

Segundo o primeiro, nas urbes africanas, a realidade viva e o universo quotidiano imediatamente observáveis... são os de miríades de pequenos empregos no centro ou na periferia das cidades. Estas aparecem, por excelência, como o mundo da troca e do mercado, dos mercadores que vendem sem previsões a longo termo, dos artesãos que fabricam em pequena quantidade ao lado das grandes unidades industriais, dos vendedores ambulantes nas proximidades dos 
supermercados reservados às classes privilegiadas; é o mundo das actividades multiformes, ... de barracas de pau-a-pique e barro ou de materiais apanhados aqui e ali; nas ruelas «agitam-se massas confusas, que se entrechocam e gritam; tudo é movimento, palavras e desordem». Ainda mais adiante acrescenta que «os pequenos empregos parecem inumanos ao passeante estrangeiro, muitas vezes folclóricos ou ultrapassados», mas engenhosos para a satisfação das necessidades do maior número... Nos mercados animados vende-se à unidade $\mathrm{e}$ as suas receitas são fracas. O mercado é um lugar de comunicação e de relações com-plexas... Mesmo os que fazem pequenos roubos, os vendedores de tabuleiro ou de pano estendido no chão, os engraxadores de sapatos, ao avistarem a polícia, reproduzem o jogo do polícia e dos ladrões... (HUGon, 1982).

Imagens muito mais fortes do início e da expansão de um grande mercado, e das suas relações com a parte formal da economia urbana, foram fixadas pelo escritor e sociólogo angolano acerca do Roque Santeiro (nome de personagem principal de uma telenovela brasileira de grande êxito), em Luanda, que pode ser considerado, senão o maior, pelo menos um dos maiores mercados informais da África. Segundo o autor, na hora de maior afluência poderão estar nele «cem mil pessoas» e «um milhão» passará por aí «todos os dias». O mercado nasceu «quando alguns vendedores, escorraçados de outros mercados da cidade» (também informais, ou «paralelos» na linguagem citadina), «fechados manu militari, aproveitaram aquele terreno vago do alto da barroca, depois da lixeira acima do porto, para montarem as pequenas bancas. Zona privilegiada, as mercadorias escapavam do porto, roubadas ou contrabandeadas sem pagar alfândega, ficavam logo ali à venda. Além disso, pela estrada vinham os produtos agrícolas dos lados do Cacuaco» (área ao norte de Luanda). «E, como, sobretudo, as autoridades não controlavam nada, apesar de haver duas esquadras a menos de quinhentos metros, de um lado e do outro, o mercado foi crescendo em clandestinidades abertas aos olhos de todos. Não havia dia sem aparecer banca com novos produtos. Depois foram barracas feitas de paus e luandos» (esteiras).

«Nesse tempo dos começos, princípios dos anos 80, era muito seguro. Vinham senhoras dos bairros ricos, sozinhas, fazer as compras. Aqui tinham certeza de tudo encontrar, mesmo o que não aparecia em nenhuma loja, mais barato que em qualquer sítio e em total segurança». Todavia, o mercado de Roque Santeiro tomou, rapidamente, outras características, que o autor descreveu com ironia amarga. «Depois chegou o progresso: bares, restaurantes, negócios de prostituição, venda de drogas, ladrões, assassinos a soldo, imigrantes indocumentados, falsificadores de passaportes, de cartas de condução, casinos, enfim uma Nova Iorque de esteiras, poeira e lixo. Quem precisasse de um carro em segunda mão, muitas vezes roubado mas de origem difícil de identificar, no Roque o podia comprar e mais à carta de condução e ainda tinha uma lição rápida, pelo menos para aprender a levar o veículo até casa. Quem quisesse ir aos Estados Unidos mas que estivesse por alguma razão incapacitado para tal, não tinha maka» (problema, dificuldade, discussão), «comprava passaporte já 
com visto de entrada, gentileza de um americano que viera para Angola ensinar democracia em cursos de duas horas e tivera acesso aos carimbos protegidos pelo FBI, CIA, e PQP. Quem procurasse dois tipos para darem uma lição a um rival, desde a carga de porrada até ao escalpe a frio, com desaparecimento eterno, era só saber procurar nas tendas da especialidade. Daí o célebre provérbio, que outros depois copiaram, se não tem no Roque é porque ainda não foi inventado» (PePETEla, 2001).

Acrescento algumas linhas em tons mais sóbrios, oferecendo outros tipos de relações entre o informal e o formal: no Roque «se encontrava a verdadeira bolsa de valores de Angola, onde se estabelecia o curso real das moedas e o preço dos produtos. E de onde partiam as mercadorias para os outros mercados e para os vendedores de rua da cidade». A propósito de bolsa de valores não posso deixar de recordar as palavras de Alain Morice, num artigo de 1985 sobre as actividades económicas em Luanda, no qual assinalava a existência de dois mercados de bens e de moeda (o legal e o ilegal), e dois sistemas de determinação de rendimentos (o nominal e o real, este também subdividido em legal e ilegal); e o facto de verificar que, na comparação de preços dos mesmos bens no mercado legal e no mercado não legal, eles estavam numa proporção quase constante e comparável à das taxas de câmbio legal e ilegal das divisas estrangeiras (MORICE, 1985).

Já referi, anteriormente, que as actividades do sector informal nem sempre são fáceis de discernir nas estatísticas, pois comportam trabalhadores em casa, por conta própria ou de outro, empregados estacionais ou de tempo mais curto, pessoas em segundos empregos ou formas de pluriactividade, etc. sendo de destacar, pela sua importância numérica, os que desempenham actividades nas ruas (artífices, vendedores, etc.), quer fixados, com alguma permanência, num determinado local, quer os de itinerância constante, assunto que tratarei mais adiante.

Por ora relevo a importância e complexidade do aumento da população urbana por entrada de gente, não só do mundo rural como também de estrangeiros, que acaba por engrossar as actividades do sector informal. A título de exemplo escolhi dois estudos de 1982 e 1985 sobre os pequenos ofícios em Abidjan, a capital da Costa do Marfim, que abrigava imigrantes de cinco países fronteiriços - Libéria, Guiné-Conakry, Mali, Burkina Faso e Ghana - e de outros mais distantes como Mauritânia, Senegal, Benim, Nigéria (KAKO, 1982; Touré, 1985). Naqueles anos totalizavam milhares de criaturas anónimas que apenas dispunham da imaginação para ocorrerem às suas necessidades, procurando descobrir nichos de actuação. Segundo o primeiro autor, no conjunto dos centros urbanos do país, tendo em conta todas as actividades, apenas 32\% eram nacionais e dos estrangeiros somente $7 \%$ não eram africanos (libaneses e franceses). Entre os estrangeiros africanos predominavam os do Mali (cerca de $15 \%)$, do Burkina-Faso (12\%) e da Nigéria (11\%); vinham depois os da Guiné (6\%), do Senegal (5\%), da Mauritânia (4\%) e de outras origens. Desses estran- 
geiros, $43 \%$ dos homens tinham menos de 30 anos de idade e $24 \%$ mais de 40 ; no caso das mulheres as percentagens correspondentes eram de 40 e 28 .

O quadro II resume uma amostragem de diversas situações, sendo interessante verificar a tendência de gentes da mesma origem praticarem os mesmos ofícios e a presença generalizada de vendedores, sobretudo os de rua, assunto que tem merecido estudos de pormenor pela importância numérica e variedade no sector informal de qualquer cidade. A menor informação sobre as mulheres deve-se a dois factos: se, por um lado, muitos dos imigrantes masculinos eram jovens solteiros, os que já tinham famílias (mulheres e filhos) nas suas terras de origem, chegavam isolados, aguardando a oportunidade de chamarem para junto de si as companheiras.

Quadro II - Pequenos ofícios de nacionais e imigrantes em Abidjan, em 1985 Table II - Small trades performed by nationals and immigrants in Abidjan, 1985

Costa do Marfim-Homens: Guardas, limpadores de pára-brisas, lavadores, bate-chapas e pintores de automóveis; escreventes públicos; barbeiros e cabeleireiros; plastificadores de documentos; carpinteiros e marceneiros, estofadores, pintores de casas, ladrilhadores; vendedores de diversos artigos. Mulheres: Vendedoras em mercados e em ruas (fixas e ambulantes), geralmente de produtos alimentares; costureiras; cabeleireiras; criadas domésticas e cozinheiras; lavadoras de pés.

Burkina-Faso-Homens: Guardas, criados domésticos e cozinheiros, lavadeiros, jardineiros e horticultores, pedreiros, alfaiates, vendedores em mercado ou ambulantes de artigos diversos (artesanato, alimentos confeccionados e bebidas, animais de capoeira). Mulheres: Produtoras e vendedoras de frescos (tomate, couves, milho, etc.).

Mali-Homens: Pedreiros, tijoleiros, ferreiros; mecânicos, bate-chapas e pintores de automóveis; possuidores de balanças para pesagem de pessoas; cortadores de carne; vendedores ambulantes; trabalhadores da construção civil; locatários de cadeiras para casamentos, baptismos, funerais, etc. Mulheres: Vendedoras de vários artigos, fixas e ambulantes; cabeleireiras; fabricantes de sabão.

Guiné-Conacri - Homens: Negociantes de ferro-velho; mecânicos de automóveis; reparadores de rádios; alcatifadores; costureiros; músicos em bandas populares. Mulheres: Cabeleireiras; cozinheiras; costureiras; vendedoras de tecidos; cantoras de bandas populares.

Ghana-Homens: Alfaiates ambulantes; sapateiros; cabeleireiros de penteados especiais, consoante a moda (natté-tressé, rasta, forlo-forlo, etc.); boticários; lavadores de automóveis. Mulheres: Costureiras; prostitutas de rua.

Niger-Homens: Carregadores; vendedores ambulantes de vários artigos; manicuras e pedicuras; lavadeiros; barbeiros e circuncisores; sapateiros, descamadores de peixe no porto.

Nigéria-Homens: Proprietários de boutiques; possuidores de balanças para pesagem de pessoas; vendedores de artigos diversos; cortadores; reparadores de rádios; fotógrafos; mecânicos de automóveis; vulcanizadores; alugadores de cadeiras; cabeleireiros; 'banqueiros' do povo. Mulheres: Vendedoras em mercados; vendedoras ambulantes de produtos de beleza e cabeleireiras.

Senegal-Homens: Vendedores ambulantes de tecidos, de artesanato e de café; joalheiros; restauradores. Mulheres: Vendedoras de panos e roupas, de produtos alimentares e bebidas. 
Limito-me a chamar a atenção para alguns casos originais de formas de actividades remuneradas (sublinhadas no quadro): as lavadoras de pés, os escreventes públicos e os circuncisores. No primeiro, jovens postadas à porta de mercados, algumas delas ainda crianças, ofereciam serviços de limpeza dos pés ou de calçado enlameados ou poeirentos dos frequentadores daquelas áreas. Cada uma delas tinha, como 'instrumentos' de trabalho, uma bacia ou alguidar, uma lata com cerca de 3 litros de água, renovável quando necessário, um pedaço de sabão e uma esponja. Investindo nisso algumas dezenas de francos, cobravam 5 a 10 francos CFA por lavagem, consoante os clientes e as quantidades de lama ou areia a retirar. Havia dias em que algumas dessas lavadoras podiam ganhar de 250 a 500 francos ou mais, o que lhes dava para a cobertura dos investimentos e a obtenção de lucros, uma parte dos quais servia para ajudar as despesas familiares e outra para participação em associações de poupança. O único risco era do aparecimento da polícia municipal, que podia aplicar-lhes multas elevadas, à roda dos 600 francos, ou apreender-lhes os «materiais» de trabalho.

Os escreventes públicos são de grande importância quando a maioria da população não sabe escrever nem ler. Houve tempos em que se pensou que diminuiria o número desses agentes, a quem se exige a obtenção de uma licença para o exercício da actividade. Todavia, o crescimento acelerado de imigrantes rurais, quer nacionais quer estrangeiros, a incapacidade das escolas citadinas acolherem todos quanto precisam de instrução, o aumento da iliteracia perante a complexidade burocrática cada vez maior, com formulários complicados e de preenchimento difícil, fizeram proliferar os escreventes. Muitos deles desenvolvem as suas actividades nas próprias instalações dos serviços públicos ou em locais muito próximos. Em 1985, um escrevente ainda no início da carreira podia ganhar 2 a 5 mil francos CFA por dia, e os mais antigos, com maior experiência e bons contactos, podiam fazer 20 a 30 mil, o que lhes permitia uma renda mensal superior aos salários de muitos funcionários públicos, entre os quais os de um assistente universitário. Quanto aos circuncisores, basta recordar a sua importância em sociedades que mantêm a circuncisão como um dever religioso e uma norma social: em épocas altas, sobretudo nas férias escolares, aumenta o número de intervenções porque ainda são muitos os pais que aproveitam essa altura para fazerem «desfeminizar» os filhos jovens.

Questão importante que se tem levantado é a da tipologia das actividades (comércio, artesanato, construção, transportes, prestação de serviços, intermediação financeira) consoante a forma de localização e meios de acção dos seus agentes: produtores e vendedores de rua, sedentários e ambulantes; produtores e vendedores estabelecidos em oficinas ou ateliers, em lojas, em mercados fixos, em mercados móveis, em casas com ou sem equipamentos específicos, em pátios colectivos, directa ou indirectamente relacionados com estabelecimentos do sector formal, etc., as relações de mercado interno e externo. O problema agrava-se devido à grande mobilidade de produtores e vendedores, quer no terreno quer no tipo de actividade. 


\section{Quadro III - Estrutura da economia urbana nos países da África ao sul do Sara}

(adaptado aos casos de Luanda e de Maputo)

Table III - Sub-Saharian African countries' urban economic structure (adapted to the cases of Luanda and Maputo)

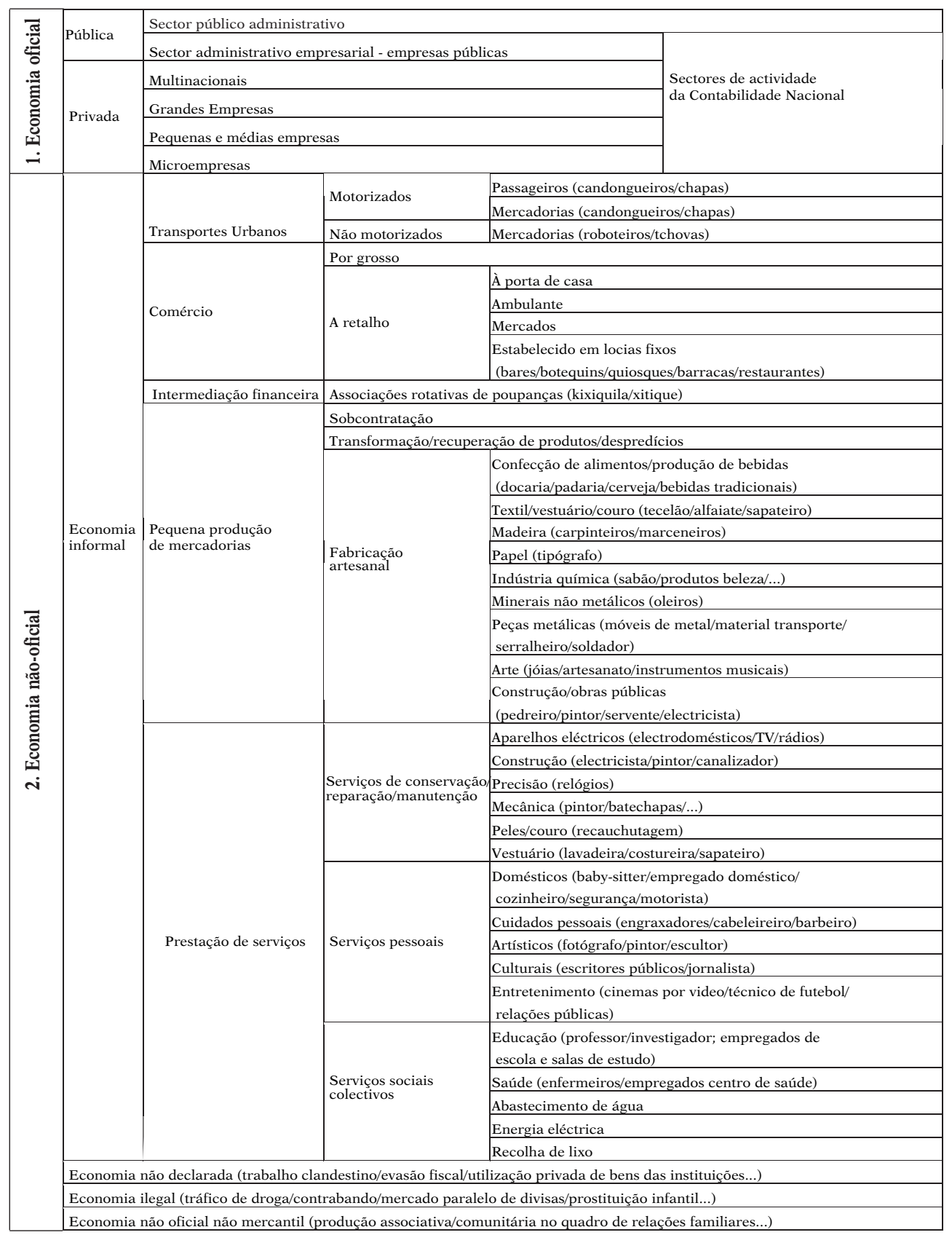


O quadro III, extraído de um trabalho recente sobre o sector informal urbano em Luanda e em Maputo (LOPES, 2003), e os anteriores mostram bem a complexidade das situações. A proposta deste autor, de uma «economia oficial» (pública e privada) e de uma «economia não oficial», incluindo-se nesta a informal, a não declarada, a ilegal e a não mercantil, faz reviver a discussão sobre o valor da expressão 'sector informal' e como definir, exactamente, o que é o informal, que têm servido de cobertura a uma grande heterogeneidade de actividades, com segmentos muito diversificados (Hugon, 1988).

Os produtores e vendedores de rua, porque totalizam percentagens elevadas e continuam em expansão, porque testemunham a forte atomização do sector informal, têm merecido atenção especial. Utilizando mais uma vez o estudo sobre Abidjan, de cerca de 243 mil pessoas recenseadas, apenas $43 \%$ tinha actividades sedentárias e, destes, a maioria estava em actividades de rua. Em menos de dez anos mais que duplicaram e estimava-se que em 1990 haveria quase tantos trabalhadores de rua como funcionários dos serviços públicos (TouRÉ, 1981 e 1985; KAKO, 1982), resultados impressionantes quando se tem em conta o empolamento excessivo da função pública em países em desenvolvimento.

Por isso mesmo selecciono os trabalhadores de rua para acrescentar algumas notas. Há os sedentários, os semi-sedentários e os ambulantes, os que expõem os seus artigos em bacias ou alguidares, em cestos ou sobre esteiras, sobre banquetas, mesas ou padiolas, em soleiras de portas, em parapeitos de janelas, os que possuem veículos (carretas, bicicletas, etc.) ou pequenas barracas. Existem especializações entre os vendedores ambulantes, a que os autores de língua inglesa, referindo-se a alguns casos específicos, têm dado certa importância, como, por exemplo, os hawkers e os peddlers (GEERTZ, 1963). Na língua portuguesa, ainda que caídas em desuso, sobretudo em Portugal, correspondem-lhes as expressões de mascates e bufarinheiros. De uma maneira muito geral, os primeiros caracterizavam-se pela venda de fazendas ou tecidos, objectos manufacturados como jóias, tapetes, etc., e os segundos pela de quinquilharias ou bugigangas, agulhas, linhas, rendas, sabonetes, etc.

As dificuldades de estudo dos produtores e vendedores de rua assentam sobretudo na colheita e tratamento de dados. As estatísticas normais, quer demográficas quer do trabalho, não os registam e algumas metodologias propostas ainda estão em fase experimental. Os inquéritos mais usuais incluem questões como as da caracterização demográfica (origem geográfica, sexo e idade) e sócio-económica (etnia ou grupo social, estado familiar, ganhos e perdas), da data de início da actividade, das ocupações anteriores, das modalidades de instalação do local de actividade, das formas de aquisição (fornecedores e formas de pagamento) e descrição das mercadorias, dos regimes de trabalho, independente ou dependente, das modalidades de fixação de preços, dos níveis de rendimentos, da competitividade entre vendedores de rua e entre eles e o comércio formal, dos relacionamentos com as autoridades, etc. O questionário pode ainda incidir sobre tópicos ligados a medidas de políticas urbanas e de apoio social, a formas tradicionais de solidariedade e de criação de poupanças, e outros (CHARMES, 1982 e 1998). 
Aos tradicionais produtores e vendedores de tudo, juntam-se aqueles que trocam localizações fixas, em casas ou pátios, por modos ambulativos: por todo o lado aparecem costureiros de pequenos trabalhos ou remendos com as suas máquinas à cabeça; cabeleireiros e barbeiros com os seus apetrechos de profissão e bancos para os clientes; reparadores de bicicletas e de automóveis, carpinteiros, canalizadores e electricistas, pedreiros e ladrilhadores com as suas caixas de ferramentas, vendedores de alimentos e bebidas com as suas padiolas ou carrinhos, etc., etc. É de sublinhar que, entre os vendedores de rua, bem como noutros segmentos do sector informal, as mulheres têm posições de relevo, quer pelo número, quer pela antiguidade. Valendo-me, novamente, do trabalho de Mário Adauta de Sousa acerca do sector informal de Luanda, os resultados estatísticos sobre o género do chefe do agregado familiar revelaram que a maioria era de mulheres inseridas em actividades comerciais, o que sugere que quaisquer medidas dirigidas ao sector também deverão ter esse facto em consideração (SouSA, 1998).

\section{CONCLUSÃO}

Este conjunto de notas e reflexões dá ideia da complexidade dos desafios e das novas perspectivas que se abrem aos investigadores das ciências humanas e sociais, e aos governantes e planeadores que carecem de estudos que os primeiros podem levar a cabo. Mas terão as cidades (sublinho que foram estas as minhas referências de base, tendo deixado de lado, de motu proprio, o mundo rural) dos países em desenvolvimento, nomeadamente as africanas subsarianas, a exclusividade do sector informal? Não, de modo algum! O informal é um aspecto universal da economia de todos os tempos, que nas cidades dos países em desenvolvimento, por motivos bem conhecidos, possui maior relevo e perenidade. O sector informal está presente até mesmo em cidades dos países mais desenvolvidos, do grupo dos 7: existe em Nova Iorque, em Londres, em Paris, em Berlim, em Roma, e muitas outras. Em Moscovo, após o desmembramento do império soviético, de que era a capital, proliferou, com nítida visibilidade, o sector informal em todos os campos de actividade. Mas nem é preciso ir muito longe: basta recordar o compêndio variado e complexo de actividades do sector informal em Lisboa, no comércio, na indústria, nos serviços, nos mercados de emprego e financeiro.

Os temas que escolhi para homenagear Carlos Alberto Medeiros são aliciantes e apontam para a necessidade de estudos pormenorizados de geografia humana, de história, de economia, de sociologia, de antropologia, de direito, sobretudo em regime interdisciplinar, de modo a haver a possibilidade de distinguir e comparar, no tempo e no espaço, o que é formal e o que é informal, esclarecer os seus relacionamentos e as formas intermédias. E para encerrar a minha contribuição nada melhor do que valer-me da autoridade do Colega e Amigo Adelino Torres, economista com vivência de África e reflexões importantes sobre 
assuntos africanos, quando sublinhou que o continente «enfrenta desafios consideráveis e a sua situação parece a muitos desesperada». Há, todavia - e continuo a citá-lo, com algumas alterações -, «uma diferença profunda» entre o especialista teórico das ciências sociais, e não apenas o economista, «que escreve, de longe, sobre a África», com «tendência para acentuar os aspectos negativos da crise, apontando a falta de competitividade, os bloqueios do crescimento e a fraqueza dos investimentos», e aquele «que tem conhecimento directo do terreno e observa factores fortemente positivos de criatividade nas iniciativas populares (frequentemente espontâneas), de emergência de novas organizações e de manifestações de um dinâmico espírito empresarial de que as estatísticas não falam» (ToRRES, 1999) e que, acrescento eu, muitos observadores, até mesmo alguns africanos, pecam por continuarem a querer vê-las através de ópticas e teorias forjadas no mundo dito Ocidental, tomadas como verdades únicas.

\section{BIBLIOGRAFIA}

AbDaimi, M. El (1989) - Le financement informel. Problématiques, typologie et évaluation à partir d'enquêtes à Marrakech et dans le Sud marocain. Revue Tiers Monde, 30 (120): 869-879.

Amaral, I. do (1968)-Luanda. Estudo de geografia urbana. Junta de Investigações do Ultramar, Col. Memórias, 53, Lisboa.

AmaraL, I. do (1985) - Notas bibliográficas sobre as cidades do Terceiro Mundo. Finisterra - Revista Portuguesa de Geografia, XX(39): 163-172.

AmaraL, I. do (1985) - Notas bibliográficas sobre as cidades do Terceiro Mundo. Finisterra - Revista Portuguesa de Geografia, XX(40): 368-373.

AmaraL, I. do (1987) - Notas bibliográficas sobre as cidades do Terceiro Mundo. Finisterra - Revista Portuguesa de Geografia, XXII(44): 361-370.

Amaral, I. do (1988) - A propósito das cidades do Terceiro Mundo. Garcia de Orta-Série de Geografia, XIII(1-2): 1-23.

Amaral, I.; CARneiro, L. (1987) - Notas e recensões: Publicações recentes sobre cidades em África. Garcia de Orta-Série de Geografia, XII(1-2): 67-82.

Amin, А. T. , ed. (1996) - Apresentação. Regional development dialogue. 17 (1).

ANDRADE, X. (1992) - Para uma nova reflexão sobre o sector informal citadino. Estudos Moçambicanos, 11-12: 77-92.

BIENEFELD, M.A. (1987) - The informal sector and peripheral capitalism: the case of Tanzania. Institute of Development Studies Bulletin, 6 (3): 53-73.

BREMAN, J. (1976) - A dualistic labour system? A critique of informal sector concept. Economic and Politic Weekly, 11 (48): 1870-1875; 11 (49): 1905-1908; 11 (50): 1939-1944.

BROMLEY, R., ed. (1979.) - The urban informal sector. Pergamon, Oxford.

Bromley, R.; GerRY, C., eds. (1979) - Casual work and poverty in Third World cities. Wiley, Chichester.

CHARMES, J. (1982) - Le secteur non structuré à Niamey. OIT, Adis-Abeba. 
Charmes, J. (1988) - Street vendors in Africa: data and methods. PNUD, Nova Iorque.

DRAKAKIS-SMITH, D. (1990) - Food for though or though about food: urban food distribution systems in the Third World. In R. Potter e A. Salau, eds., Cities in the Third World. Mansell, Londres: $100-120$.

GEERTZ, C. (1963) - Peddlers and princes: social change and economic modernization in two Indonesian towns. The University of Chicago Press, Chicago.

Gilbert, A. e Gugler, J. (1982)-Cities, poverty and development: urbanization in the Third World. Oxford.

Hugon, Ph. (1982) - Secteur souterrain ou réseaux apparents. In I. DEBLÉ, Ph. HUGON et al., Vivre et survivre dans les villes africaines, Institut d'Études du Développement Économique et Social-Col. Tiers Monde et Presses Universitaires de France, Paris.

Hugon, Ph. (1999) - A Economia de África. Vulgata, Lisboa.

KAKO, O. (1982) - L'attraction des capitales: le cas d'Abidjan. In I. DeBlé, Ph. Hugon et al., Vivre et survivre dans les villes africaines. Institut d'Études du Développement Économique et SocialCol. Tiers-Monde et Presses Universitaires de France, Paris.

Lomnitz, L. (1977) - Mechanisms of articulation between shanty towns settlers and urban system. Burg Waterstein.

LOPES, C. (2003) - O sector informal urbano em Luanda e Maputo: contrastes e semelhanças. In I. Castro Henriques, coord., Novas Relações com África: que Perspectivas? Actas do III Congresso de Estudos Africanos no Mundo Ibérico, 2001. Vulgata, Lisboa.

McGEE, T.G. (1996) - On the utility of dualism: the informal sector and mega-urbanization in developing countries. Regional Development Dialogue, 17(1): 1-15.

MedeIRos, C.A. (1970) - L'Évolution récente de la sucrerie Beauport (Guadeloupe). Étude de géographie humaine. Edição policop. do Autor, Bordéus.

Medeiros, C.A. (1976) - A Colonização das Terras Altas da Huíla (Angola). Estudo de geografia humana. Centro de Estudos Geográficos, Col. Memórias, 2, Lisboa.

Miracle, M. P.; Miracle, D. S.; Cohen, L. (1980)-Informal savings mobilization in Africa. Economic Development and Cultural Change, 28(4): 701-724.

Morice, A. (1985) - Commerce paralèle et troc à Luanda. Politiques urbaines, Politiques Africaines, 17: $105-120$.

Morin, E. (2000) - Les sept savoirs nécessaires à l'éducation du futur. Seuil, Paris.

O'Connor, A. (1983 e 1986) - The African City. Hutchinson Library for Africa, Londres.

OIT (1981) - Urban informal sector in developing countries. Genebra.

PaIX, C. (1972)-Approche théorique de l'urbanisation dans les pays du Tiers Monde. Revue Tiers Monde, 50: 269-308.

Pepetela-Santos, A. C. P. (2001) - Jaime Bunda. Agente secreto. Estórias de alguns mistérios, Publicações Dom Quixote, Lisboa.

PNUD (1998) - Relatório do Desenvolvimento Humano. PNUD. Lisboa.

Roberts, B. (1978) - Cities of peasants. Edward Arnold, Londres.

Santos, M. (1975)-L'Espace partagé. Les deux circuits de l'économie urbaine des pays sous-développés. Ed M.Th. Génin, Paris.

Sethuraman, S.V. (1976) - The Urban informal sector. International Labour Review, 114: 69-81. 
SethuRAman, S.V. (1977) - The Urban informal sector in Africa. International Labour Review, 116: 343-352.

SousA, M. A. (1998)-Sector informal de Luanda. Contribuição para um melhor conhecimento. Luanda.

TINKER, I. (1997, ed.) - Street foods: urban food and employment in developing countries. Oxford University Press, Nova Iorque.

Torres, A. (1999) - Prefácio. In Ph. HUGON, A Economia de África. Vulgata, Lisboa.

Touré, A. (1981) - La civilisation quotidienne en Côte d'Ivoire. Procès d'occidentalisation. Karthala, Paris.

Touré, A. (1985) - Les petits métiers à Abidjan. L'imagination au secours de la 'conjoncture'. Karthala, Paris.

WARING, M. (1999) - Counting for nothing: what men value and what women are worth. University of Toronto Press, Toronto.

YASMEEN, G. (2001) - Stockbrokers turned sandwich vendors: the economic crisis and small-scale food retailing in Southeast Asia. Geoforum, 32(1): 91-102. 